\title{
Effect of Deposition Time on the Morphological Features and Corrosion Resistance of Electroless Ni-High P Coatings on Aluminium
}

\author{
N. Sridhar and K. Udaya Bhat \\ Department of Metallurgical and Materials Engineering, NITK Surathkal, Karnataka 575025, India \\ Correspondence should be addressed to K. Udaya Bhat; udayabhatk@gmail.com
}

Received 26 December 2012; Revised 13 April 2013; Accepted 13 April 2013

Academic Editor: Ram Katiyar

Copyright (C) 2013 N. Sridhar and K. Udaya Bhat. This is an open access article distributed under the Creative Commons Attribution License, which permits unrestricted use, distribution, and reproduction in any medium, provided the original work is properly cited.

High phosphorus Ni-P alloy was deposited on aluminium substrate using electroless deposition route. Using zincating bath, the surface was activated before deposition. Deposition time was varied from 15 minutes to 3 hours. Deposit was characterised using scanning electron microscope with energy dispersive spectroscope, X-ray diffraction, and microhardness tester. The corrosion resistance was measured using Tafel extrapolation route. The medium was aqueous $5 \% \mathrm{HNO}_{3}$ solution. The analysis showed that the deposit consisted of nodules of submicron and micron scale. The predominant phase in the deposit was nickel along with phosphides of nickel. Compared to substrate material, deposit showed higher hardness. With increase in deposition time, the deposit showed more nobleness in $5 \% \mathrm{HNO}_{3}$ solution and nobleness reached a limiting value in 1 hour deposition time.

\section{Introduction}

Electroless plating is a well-established surface modification process involving deposition of a metal-metalloid alloy coating on various substrates [1]. Although, a variety of metals (or alloys) can be electrolessly plated, electroless Ni-P coatings have received widespread acceptance, because they provide high hardness, excellent resistance to wear, abrasion, and corrosion [1]. In general, electroless nickel deposits are classified into three categories: low P (1-5 wt\%), medium P (5-8 wt\%), and high P (9 wt\% and above). Studies have shown that as-coated high $\mathrm{P}$ deposits could be fully amorphous mixtures of microcrystalline and amorphous phases with other phases like $\mathrm{Ni}_{5} \mathrm{P}_{4}, \mathrm{Ni}_{12} \mathrm{P}_{5}$, and $\mathrm{Ni}_{5} \mathrm{P}_{2}[2,3]$. Studies have also shown that a high phosphorus amorphous deposit crystallises into metastable $\mathrm{Ni}_{12} \mathrm{P}_{5}$ phase before transferring into $\mathrm{Ni}$ and $\mathrm{Ni}_{3} \mathrm{P}$ phase [3]

In general, electroless deposition of Ni-P alloy is characterised by the reduction of $\mathrm{Ni}$ ions onto a substrate immersed in a bath of aqueous solution of Ni metal ions. A chemical reducing agent in solution supplies the electrons required for converting metal ions to metal deposit. The electroless nickel deposits obtained using sodium hypophosphite as a reducing agent are binary alloys of nickel and phosphorous. The parameters which determine the $\mathrm{P}$ content in electroless $\mathrm{Ni}-\mathrm{P}$ deposits are known to be the nickel and reducing agent concentrations, type and concentration of the inhibitor and accelerator in the plating solution, and $\mathrm{pH}$ and temperature of the solution [4]. Generally, deposits from acidic baths have a higher level of $\mathrm{P}$ content, sometimes exceeding 25 at \%P [4]. It is also reported that the high phosphorous deposits are supersaturated solid solution of $P$ dissolved in crystalline nickel [4]. Electroless nickel-phosphorus alloy depositions can be done on various types of substrates, namely, steels, aluminium alloys, and magnesium alloys. Electroless nickel alloy deposition on aluminium substrate is a potential one in the areas of the joining of aluminium alloy with another dissimilar alloy, electronic applications, and applications where wear and corrosion resistance are of maximum interest $[5,6]$. However, electroless nickel plating on $\mathrm{Al}$ suffers from a reliability problem due to poor adhesion between nickel and aluminium substrates. Several methods have been tried to improve the adhesion between nickel and aluminium. It is reported that an intermediate zincate process helps in improving the adhesion between nickel and aluminium $[5,7]$. 
When applied on to an $\mathrm{Al}$ substrate, the electroless Ni-P alloy coatings can give a hard and wear resistant surface [6]. High phosphorous Ni-P alloys are generally more resistant to acids. The crystallisation and presence of phosphorous in the form of phosphides reduces the corrosion resistance [6]. Since many years, aluminium has been considered as a replacement material for steel in applications where the structure weight is an important factor. The obtainable mechanical properties of aluminum like wear resistance, friction coefficient, and strength can be altered by electroless Ni-P plating on steel. By doing so, electrochemical properties like corrosion resistance are also changed. The properties of these coatings are affected by the coating microstructure [8].

In electroless Ni-P deposition, the density of the nucleation sites determines the adhesion properties of the endfilm. The nucleation activity itself is a probabilistic phenomenon [4]. The Ni-P deposition starts at specific activation sites on the surface and continues on these points. Zincating process helps in initiation of the electroless deposition on Al substrate. The bulk of the zinc immersion deposit is dissolved in acid electroless nickel plating solutions, exposing the aluminium and initiating autocatalytic deposition process $[9,10]$. As deposition progresses, islands are formed around these nucleation sites. The islands grow in size until they merge and a continuous film develops. Hence metal island density and island size distribution are time dependent functions during the immersion period in the metalizing bath [4]. Nucleation also affects lateral joining of the growing crystallites due to physical impingement, and hence features of the deposits like morphology, microporosities, and thermal stresses of the deposit are expected to change [10].

In a number of nitric acid based industrial applications, such as nitric acid based explosives, catalytic decomposition of ammonia, and processing of ammonium nitrate, aluminium comes in contact with nitric acid of various concentrations [11]. For aluminium and its alloys, electroless deposition can provide a protective coating with a set of improved wear resistance, mechanical properties, and corrosion resistance [12-14].

\section{Materials and Experiments}

Commercial pure Al strips of AISI grade 1100 were used as the substrate for electroless Ni-P deposition. The dimensions of the strip were $3 \mathrm{~mm}$ thick, $40 \mathrm{~mm}$ width, and $150 \mathrm{~mm}$ length. The plates were polished metallographically with various grades of emery papers. Since aluminium exposed to air is expected to be covered by a dense oxide coating, it is removed by dipping it in 50 vol\% nitric acid solution for few seconds. During this step, nitric acid solution removes existing oxide layer and a thin, uniform oxide film on the aluminium surface is formed. It is expected that this step helps in getting a uniform zinc coating during zincating process [9]. Zincating was done with the help of an acid zinc immersion bath, consisting of zinc sulphate $(720 \mathrm{~g} / \mathrm{L})$ and hydrofluoric acid $(17.5 \mathrm{~mL} / \mathrm{L})$ [9]. Zincating was done for 5 minutes.

Electroless coating was done using bath 4 listed in the ASM Handbook [15]. The bath composition and operating parameters are given in Table 1. Nickel sulphate was
TABLE 1: Bath compositions and processing parameters used for electroless deposition.

\begin{tabular}{lccc}
\hline Constituent & $\begin{array}{c}\text { Value } \\
\text { (gram/litre) }\end{array}$ & Parameter & Value \\
\hline Nickel sulphate & 21 & $\mathrm{pH}$ & $4.3-4.6$ \\
Sodium hypophosphite & 24 & Temperature $\left({ }^{\circ} \mathrm{C}\right)$ & $88-95$ \\
Lactic acid & 28 & - & - \\
Propanoic acid & 2.2 & - & - \\
\hline
\end{tabular}

the source of nickel and sodium hypophosphite was the reducing agent. Lactic acid was used as complexing agent and propanoic acid as buffer. The samples were dipped in the electroless bath for $15 \mathrm{~min}, 30 \mathrm{~min}, 1$ hour, 2 hours, and 3 hours, respectively. Using a glass rod, the bath was continuously stirred during deposition.

The morphology of the samples was characterised using scanning electron microscope (SEM, JEOL make, model 6380LA). Elemental compositions at various regions in the coating were estimated using energy dispersive spectroscopy (EDS) attached to SEM. Crystallinity of the coating was studied using X-ray diffractometer (XRD, machine JEOL make, JPX 8$). \mathrm{Cu}_{\mathrm{K} \alpha}(\lambda=1.5418 \AA)$ was the radiation used. Hardness of the sample was measured using Vickers microhardness tester. Load used for hardness measurement was $50 \mathrm{~g}$. Corrosion resistance of the $\mathrm{Ni}-\mathrm{P}$ coatings was studied using Potentiostat-Galvanostat (VersaSTAT-3, Princeton Applied Research) using three electrode cells and the potentials were measured using silver-silver chloride $\left(\mathrm{Ag} / \mathrm{AgCl} / \mathrm{Cl}_{\text {sat }}^{-}\right)$as reference electrode. During corrosion study, only the coated surface was exposed to corrosion medium. The aqueous $5 \% \mathrm{HNO}_{3}$ solution was used as corrosion medium. The open circuit potential (OCP), corrosion potential $\left(E_{\text {corr }}\right)$, and corrosion current density $\left(i_{\text {corr }}\right)$ were estimated using Tafel extrapolation method. Morphology of the corroded samples was investigated using SEM and used in understanding of corrosion process.

\section{Results and Discussion}

Figures 1(a) to 1(e) show morphology of Ni-P deposits deposited for time intervals of 15 minutes, 30 minutes, 1 hours, 2 hours, and 3 hours, respectively. Ni-P deposit deposited for $15 \mathrm{~min}$ (Figure 1(a)) is incomplete. The patches of Ni-P alloy deposited over substrate material are clearly visible. Compared to that, deposit deposited for 30 minutes and above covers the substrate almost completely. The surface topography of Ni-P deposit showed the spherical nodular structure with very fine and compact grains [8].

Figure 2 shows nodule size distribution measured over a large number of nodules. In Table 2 mean nodule size and standard deviation are presented for all deposits. We see that in all cases the nodule size is relatively small and all deposits show a clear peak in the distribution curve.

Electroless Ni-P deposition is a nucleation and growth phenomena which are time dependent. Nucleation is an important step in forming an adherent Ni-P coating. Nucleation activity itself is a probabilistic phenomenon. Hence, 


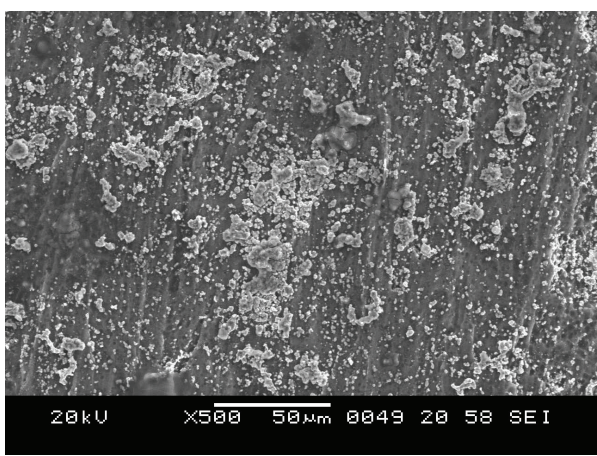

(a)

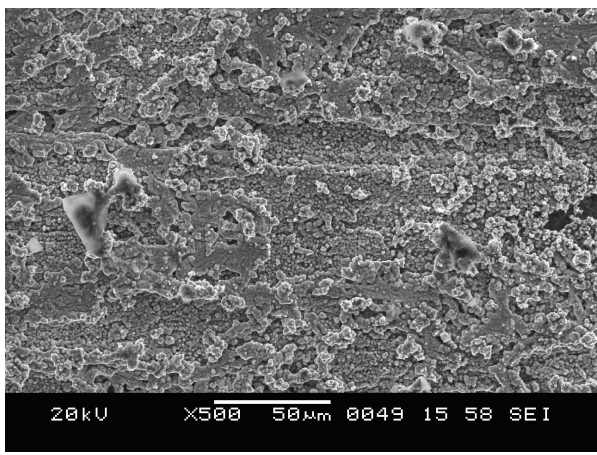

(c)

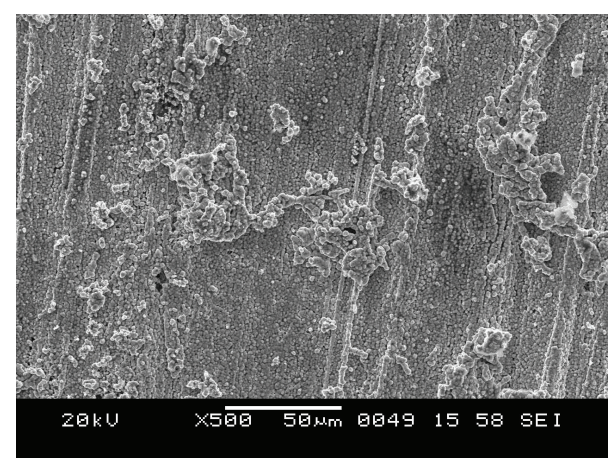

(b)

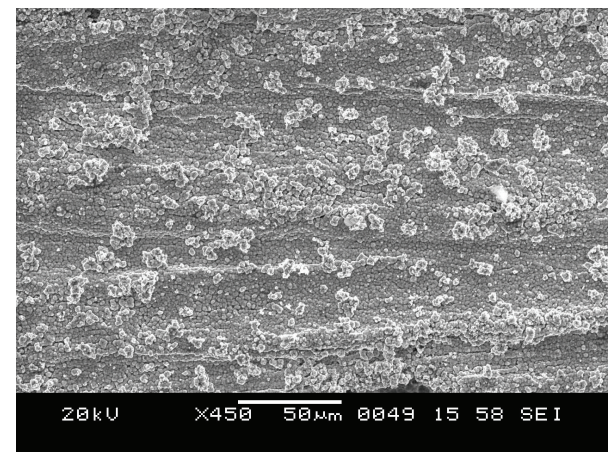

(d)

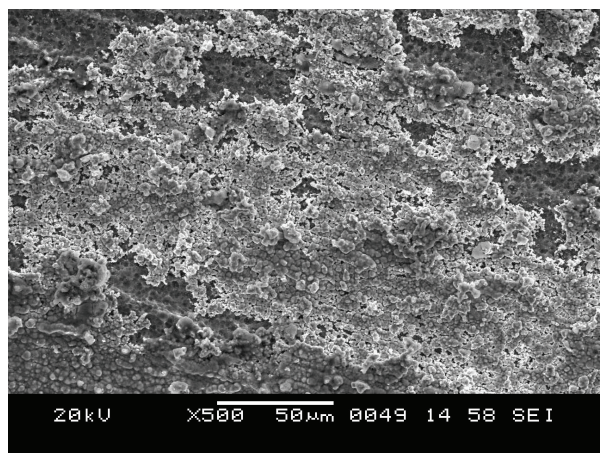

(e)

FIgURE 1: Microstructures of electroless Ni-P deposits deposited for times 15, 30, 60, 120, and 180 minutes, respectively.

TABLE 2: Mean nodule size and standard deviation for various electroless deposits.

\begin{tabular}{lcc}
\hline Deposition time (hours) & Mean $(\mu \mathrm{m})$ & Standard deviation \\
\hline $1 / 4$ & 0.81 & 0.101 \\
$1 / 2$ & 1.02 & 0.09 \\
1 & 1.23 & 0.112 \\
2 & 1.22 & 0.122 \\
3 & 1.16 & 0.11 \\
\hline
\end{tabular}

metal island density and island size distribution are time dependent functions during the immersion period in the metallizing bath [4]. Ni-P deposit deposited for 15 min clearly shows the presence of Ni-P deposits in the form of islands. This is because the nucleation events occurring on a catalysed surface are a probabilistic process. Once nucleation events take place, the Ni-P alloy grains grow into spherical nodules. It is reported that [16] the spherical nodules are the product of the autocatalytic reaction with sodium hypophosphite participating in it. The number of nucleating sites increases with time, creating more nodules. In the next stage, the nodules acted as the deposition sites for the deposition reaction and the coating was extended into $2 \mathrm{D}$ direction, centering on the spherical nodules and covering full surface. The activation of the surface using zincating solution produces small catalytic sites dispersed on the surface acting as the nuclei for electroless deposition.

The deposits deposited for longer times $(30 \mathrm{~min}$ and greater) also show the additional nodules present above the base layer. This is because the substrates like steel and aluminium become catalytic when a thin nickel deposit is 


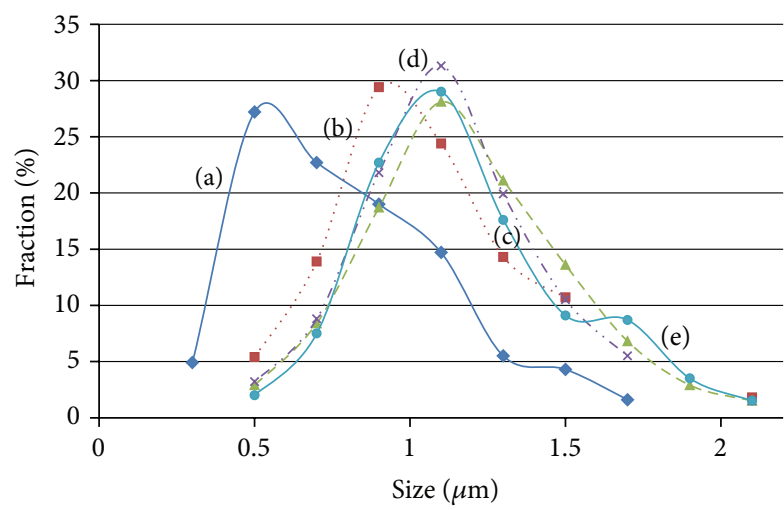

FIGURE 2: Nodule size distribution in samples deposited for various times: (a): 15 minutes, (b): 30 minutes, (c): 1 hour, (d): 2 hours, and (e): 3 hour.

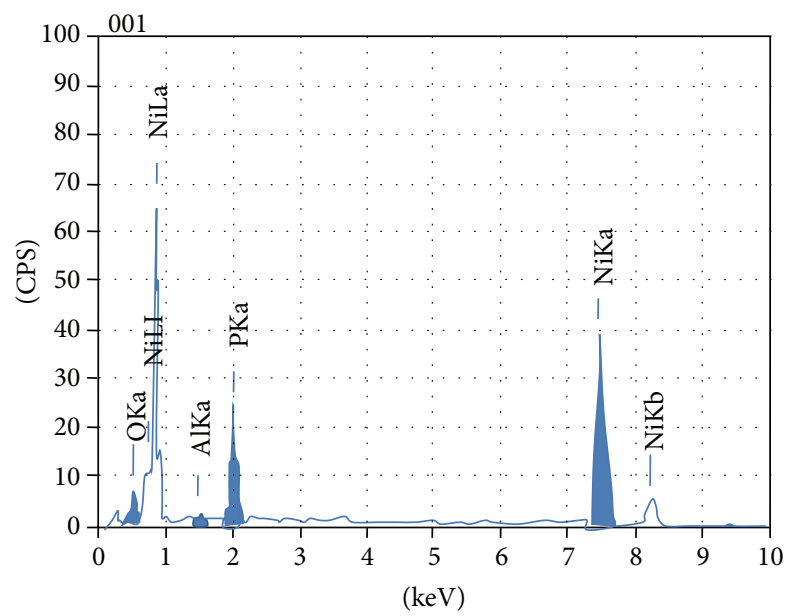

Figure 3: Profile showing EDS scan results on the total area given in Figure 1 (1-hour deposit). Ni : P ratio was 78:22 (atomic ratio).

formed over the substrate on immersion in an electroless plating bath. The catalytic sites on the initial deposits act as nucleating sites for additional nodules.

The as-formed coating has the catalytic activity required for the autocatalytic reaction, and this promoted the nucleation and growth of the coating in the third direction. The formation of a new layer on the previously deposited layer could be seen in the coatings deposited for longer dipping time and such morphologies are also reported [17]. It may be noted that the nodule size is much smaller compared to the nodule size reported in our previous work. Relatively coarse nodule size is reported in our earlier work [18]. Those deposits were under the conditions of no zincating treatment. It is reported that zincating treatment increases density of nucleation sites. When nucleation rate is high, their growth before physical impingement will be limited.

Figure 3 shows the results of EDS analysis on Ni-P deposit deposited for 1 hour measured over an area of 300 um by $250 \mathrm{um}$. The EDS result indicates that the Ni-P ratio (ration by atomic percentage) over the displayed region is about $78: 22$. EDS analysis on other deposits also showed very high

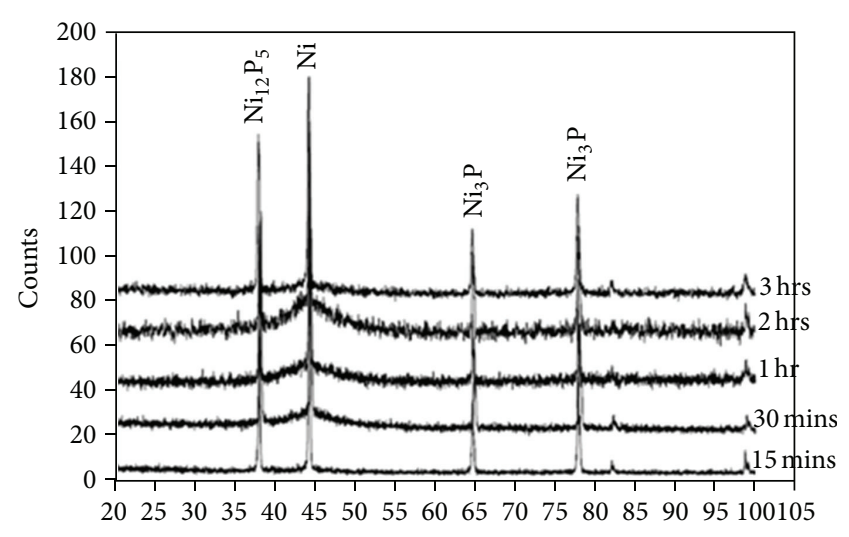

$2 \theta$

FIGURE 4: XRD plots for Ni-P deposits deposited for various times.

$\mathrm{P}$ values. It may be noted that the equilibrium solubility of $\mathrm{P}$ in $\mathrm{Ni}$ is very small [19]. The extra $\mathrm{P}$ in the deposit has introduced metastability to the deposit. Large amount of $\mathrm{P}$ dissolution during electroless deposition is reported by many investigators $[4,12]$.

Figure 4 shows XRD plots for Ni-P deposits deposited for various time durations. There is a predominant peak near 44 degree showing presence of nickel. Peak at 44 degree is wide which suggests that coating is semicrystalline-a mixture of amorphous and microcrystalline. He et al. [20] have reported a semicrystalline Ni-P alloy coating on magnesium alloy. Presence of crystalline and microcrystalline coating during electroless Ni-P deposition on steel is reported by other investigators $[1,21]$. A single broad peak indicates that the deposit is microcrystalline with preferred orientations. Single predominant peak is an indication of strong texture in the coating. Such texture in Ni-P deposition on aluminium alloy is reported by Park and Lee [22]. There are other peaks corresponding to Ni-P compounds, that is, $\mathrm{Ni}_{3} \mathrm{P}$ and $\mathrm{Ni}_{12} \mathrm{P}_{5}$. Though the literature has references for formation of various $\mathrm{Ni}-\mathrm{P}$ compounds, there is no unanimity on the type of the compound $[2,3,20]$.

Hardness. To assess the mechanical properties of the Ni-P coating microhardness measurements were done with a load of $50 \mathrm{~g}$, and Table 3 presents statistics of 10 measurements. It must be mentioned that the load is high enough to have both coating and substrate materials as interacting materials during indentation. Increase in deposition time produces a thicker coating. For a fixed indentation load, as the deposition time increases, contribution from coating towards measured hardness increases. This in turn leads to an increase in the hardness value. This clearly shows that coating is much harder than the substrate material.

\section{Corrosion Studies}

The corrosion of electroless nickel-phosphorous deposit in aqueous $5 \% \mathrm{HNO}_{3}$ solution is wet corrosion. All metals above hydrogen in the electrochemical series have a tendency to get dissolved in acidic solutions with simultaneous evolution 


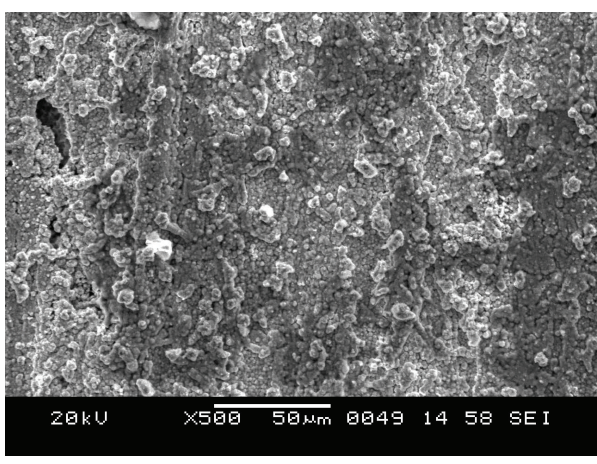

(a)

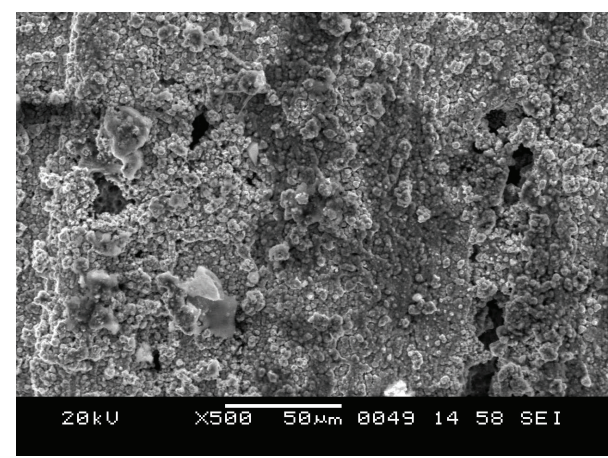

(b)

FIGURE 5: Morphology of the corroded sample indicating localised corrosion. (a) Coating deposited for 30 minutes (b) Coating deposited for 180 minutes.

TABLE 3: Measured hardness values of the coating deposited for different durations.

\begin{tabular}{lcc}
\hline Coating time & \multicolumn{2}{c}{ Hardness (Hv) } \\
& Mean & Range \\
\hline Base material & 43 & $42-44$ \\
15 minutes & 72.5 & $66-77$ \\
30 minutes & 78.2 & $74-86$ \\
1 hour & 94.7 & $87-102$ \\
2 hours & 125 & $116-145$ \\
\hline
\end{tabular}

of hydrogen. Electroless Ni-P deposits are cathodic in most of the galvanic couples. But in our system electroless Ni-P coating is a barrier coating and is expected to protect the underlying metal by sealing it off from the environment. In the beginning only the coating is exposed to corrosion environment. In such cases, anode and cathode areas are formed based on a number of parameters like local composition, crystallinity, presence of phosphorous in various forms of phosphides, and so forth.

$$
\text { At anode: } \quad \mathrm{M}=\mathrm{M}^{++}+2 \mathrm{e}^{-}
$$

Electron flows through the metal from anode regions to cathode regions. At cathode electrons are consumed by $\mathrm{H}^{+}$ ions to get liberated as hydrogen gas:

$$
2 \mathrm{H}^{+}+2 \mathrm{e}^{-}=\mathrm{H}_{2}
$$

Overall reaction is $\mathrm{M}+2 \mathrm{H}^{+}=\mathrm{M}^{++}+\mathrm{H}_{2}$

As the reaction proceeds, the anodic regions in the electroless $\mathrm{Ni}-\mathrm{P}$ coating are dissolved creating pits which facilitates penetration of corroding medium towards the substrate material. Alternatively, presence of pores in the electroless Ni-P coatings (see Figure 1) will facilitate the penetration of the corroding medium to reach the substrate. Under both situations, the coating becomes a penetrable coating, allowing passage of corroding medium towards the substrate. Such pores are clearly visible in the micrographs presented in Figure 5. Figure 5(a) shows the morphology of the coating deposited for 30 minutes and corrosion tested. Figure 5(b)

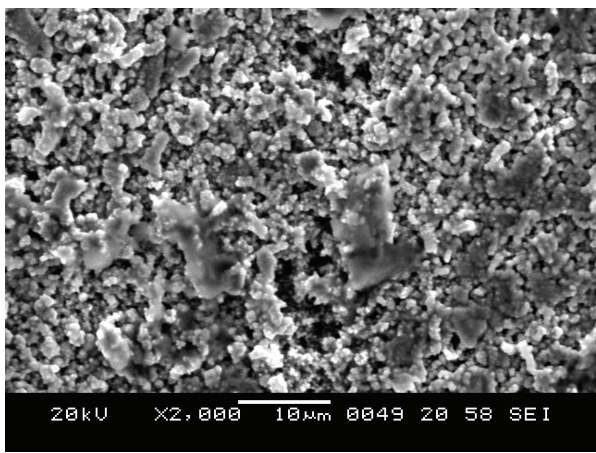

Figure 6: Micrograph showing preferential dissolution at the nodule boundaries. Magnified from Figure 5(b).

TABLE 4: OCP, $E_{\text {corr }}$, and $i_{\text {corr }}$ values estimated from the plots given in Figure 7.

\begin{tabular}{lccc}
\hline $\begin{array}{l}\text { Deposition time } \\
(\mathrm{min})\end{array}$ & $\begin{array}{l}\text { OCP } \\
(\mathrm{mV})\end{array}$ & $\begin{array}{l}E_{\text {corr }} \\
(\mathrm{mV})\end{array}$ & $\begin{array}{c}i_{\text {corr }} \\
\left(\mathrm{mA} / \mathrm{cm}^{2}\right)\end{array}$ \\
\hline 15 & 228 & 235 & 0.23 \\
30 & 275 & 270 & 0.75 \\
60 & 283 & 280 & 0.75 \\
120 & 283 & 280 & 0.85 \\
180 & 283 & 282 & 0.85 \\
\hline
\end{tabular}

shows the morphology of the coating deposited for 180 minutes and corrosion tested. Figure 6 shows a high magnification micrograph from Figure 5(b). The micrograph shows dissolution of nodule boundaries which clearly indicates preferential dissolution.

Figure 7 shows Tafel plots for various deposits in an aqueous medium of $5 \% \mathrm{HNO}_{3}$ solution. Plots clearly indicate changes in cathodic reaction taking place in substrate and coated system. The changes indicate that nucleation and growth behaviour of hydrogen bubbles change in deposited surface. Table 4 shows OCP, $E_{\text {corr }}$, and $i_{\text {corr }}$ values estimated from these plots.

The corrosion potential (OCP) shifts towards positive side with increase in deposition time. The value is stabilised 


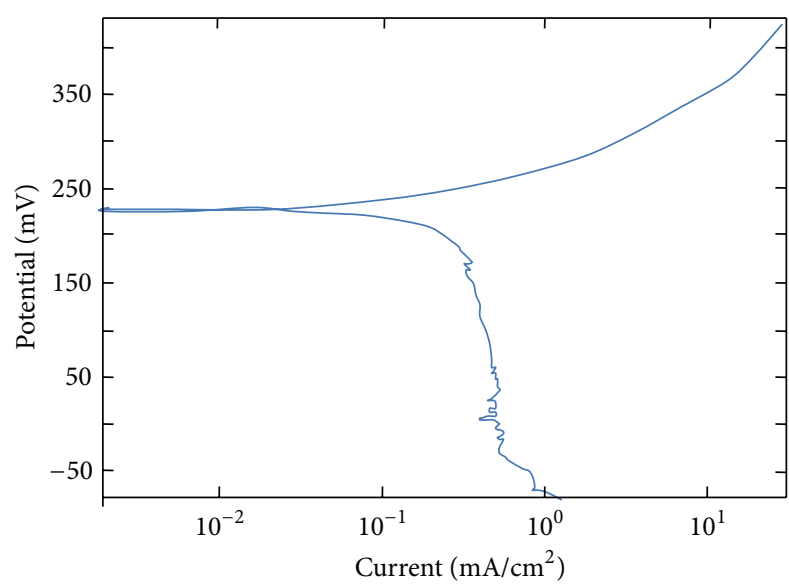

(a)

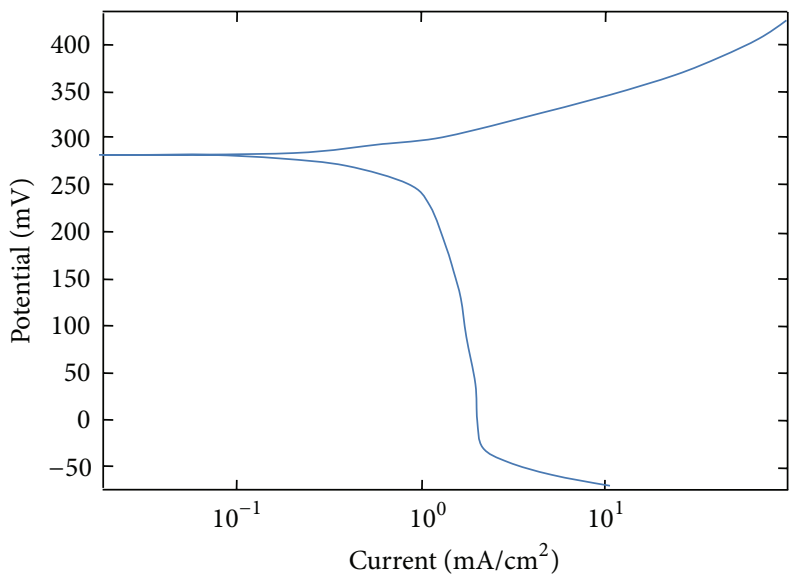

(c)

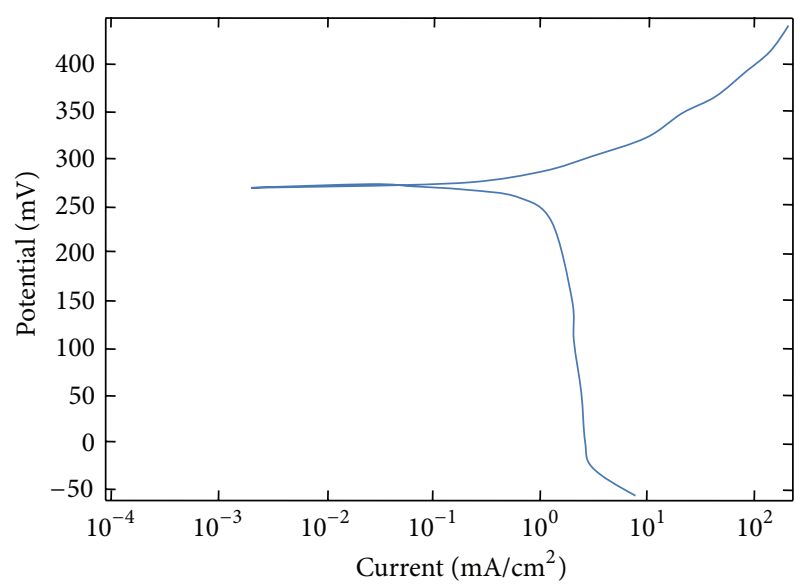

(b)

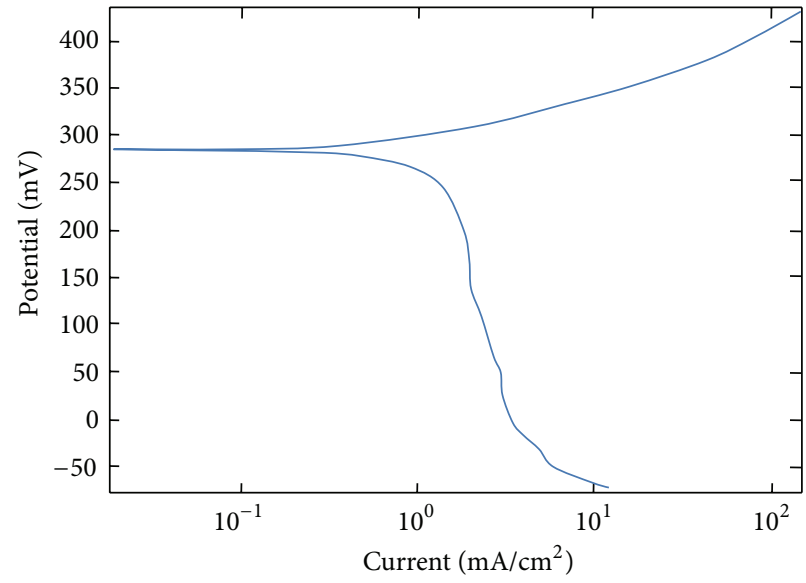

(d)

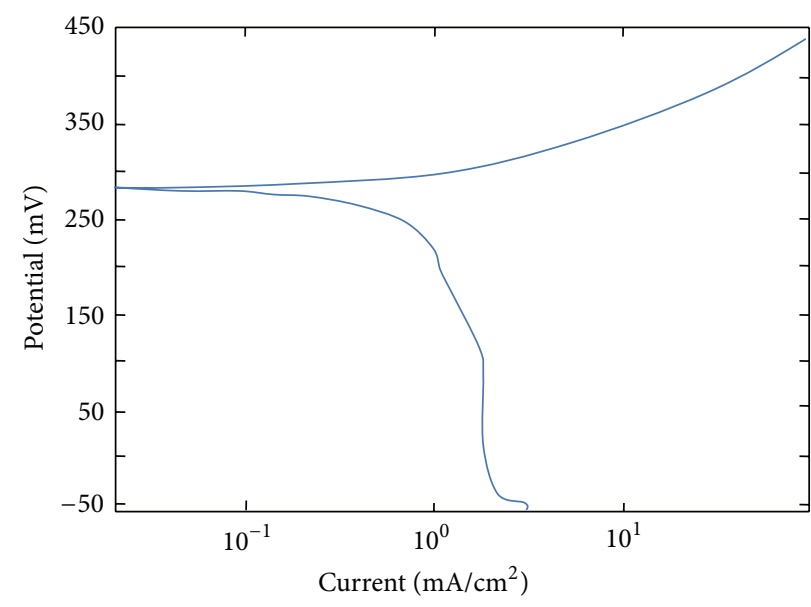

(e)

Figure 7: Tafel plots of (a) 15 minutes, (b) 30 minutes, (c) 1 hour, (d) 2 hours, and (e) 3 hours plated and corrosion tested samples.

after 60-minute deposition time. This is similar to the condition of low porosity and high porosity coatings reported by the investigators $[20,23]$. It is reported that when the coating becomes less porous, the potential shifts towards positive voltage. In the present case, an increase in the deposition time produced a coating with improved coverage, leading to a shift in the corrosion potential. After 60 minutes, the coating coverage is saturated and after that only coating is thickened. Liu et al. [24] have reported that the positive shift in the OCP value is the consequence of the lower corrosion rate reducing the demand for cathodic current. The pore structure and nodule size distribution are stabilised 
after about 60 minutes of deposition time and this is also reflected in the $\mathrm{OCP} / E_{\text {corr }}$ value. A study by Lo et al. [25] has shown that EN coating containing high $\mathrm{P}$ content reacts with electrolytes to form a layer of adsorbed hypophosphite anions. This will block the supply chain of electrolyte to the electrode surface, thereby preventing the hydration of $\mathrm{Ni}$. Though the reported investigation was with aqueous $\mathrm{NaCl}$ as the electrolyte, similar features are expected to happen in aqueous $\mathrm{HNO}_{3}$ bath. In as-received $\mathrm{Al}$ substrates, the oxide layers play an important part in preventing the reaction between aluminium substrate and medium and reducing the corrosion current.

\section{Conclusions}

Electroless Ni-high $\mathrm{P}$ deposits were deposited on pure aluminium for different time durations. Using zincating pretreatment, very fine nodules in the deposit were observed. The deposits were semicrystalline in nature and were harder than the substrate aluminium. Corrosion studies in aqueous $5 \% \mathrm{HNO}_{3}$ solution indicated that an increase in the deposition time increases nobleness of the deposit and nobleness reached a limiting value at 1 -hour deposition time.

\section{References}

[1] T. S. N. Sankara Narayanan, I. Baskaran, K. Krishnaveni, and S. Parthiban, "Deposition of electroless Ni-P graded coatings and evaluation of their corrosion resistance," Surface and Coatings Technology, vol. 200, no. 11, pp. 3438-3445, 2006.

[2] R. C. Agarwala and S. Ray, "Variation of structure in electroless NI-P films with phosphorus content," Zeitschrift für Metallkunde, vol. 79, no. 7, pp. 472-475, 1988.

[3] K. G. Keong, W. Sha, and S. Malinov, "Crystallisation kinetics and phase transformation behaviour of electroless nickelphosphorus deposits with high phosphorus content," Journal of Alloys and Compounds, vol. 334, no. 1-2, pp. 192-199, 2002.

[4] M. Schlesinger, "Electroless deposition of nickel," in Modern Electroplating by Mordechay Schlesinger and Milan Paunovicmed, pp. 447-457, John Wiley \& Sons, New York, NY, USA, 5th edition, 2010.

[5] J. G. Jin, S. K. Lee, and Y. H. Kim, "Adhesion improvement of electroless plated $\mathrm{Ni}$ layer by ultrasonic agitation during zincating process," Thin Solid Films, vol. 466, no. 1-2, pp. 272278, 2004.

[6] K. Hari Krishnan, S. John, K. N. Srinivasan, J. Praveen, M. Ganesan, and P. M. Kavimani, "An overall aspect of electroless Ni-P depositions-a review article," Metallurgical and Materials Transactions A, vol. 37, no. 6, pp. 1917-1926, 2006.

[7] P. Sahoo and S. K. Das, "Tribology of electroless nickel coatings-a review," Materials and Design, vol. 32, no. 4, pp. 1760-1775, 2011.

[8] M. M. Younan and S. A. A. El-Enine, "Electroless deposition of nickel-copper-phosphorus alloy on aluminum," Galvanotechnik, vol. 95, no. 12, pp. 2876-2881, 2004.

[9] J. Hajdu, "Surface preparation for electroless nickel plating," Electroless Plating, Fundamentals and Applications, Noyes Publication, 1990, http://www.knovel.com/.

[10] J. Sudagar, G. Bi, Z. Jiang, G. Li, Q. Jiang, and J. Lian, "Electrochemical polarization behaviour of electroless Ni-P deposits with different chromium-free pre-treatment on magnesium alloy," International Journal of Electrochemical Science, vol. 6, no. 7, pp. 2767-2788, 2011.

[11] K. F. Khaled, "Electrochemical investigation and modeling of corrosion inhibition of aluminum in molar nitric acid using some sulphur-containing amines," Corrosion Science, vol. 52, no. 9, pp. 2905-2916, 2010.

[12] W. Qin, "Microstructure and corrosion behavior of electroless Ni-P coatings on 6061 aluminum alloys," Journal of Coatings Technology Research, vol. 8, no. 1, pp. 135-139, 2011.

[13] B. Oraon, G. Majumdar, and B. Ghosh, "Improving hardness of electroless Ni-B coatings using optimized deposition conditions and annealing," Materials and Design, vol. 29, no. 7, pp. 14121418, 2008.

[14] H. Bi, K. C. Kou, K. Ostrikov, L. K. Yan, and Z. C. Wang, "Microstructure and electromagnetic characteristics of $\mathrm{Ni}$ nanoparticle film coated carbon microcoils," Journal of Alloys and Compounds, vol. 478, no. 1-2, pp. 796-800, 2009.

[15] ASM Handbook Committee, Electroless Nickel Plating, vol. 5 of Surface Engineering ASM Handbook, American Society for Materials, Materials Park, Ohio, USA, 1994.

[16] Y. Xiang, W. Hu, X. Liu, C. Zhao, and W. Ding, "A study on surface state during the pretreatment of electroless nickel plating on magnesium alloys," Transactions of the Institute of Metal Finishing, vol. 79, no. 1, pp. 27-29, 2001.

[17] T.-N. Qin, L.-Q. Ma, Y. Yao, C. Ni, X.-Y. Zhao, and Y. Ding, "An in situ measure method to study deposition mechanism of electroless Ni-P plating on AZ 31 magnesium alloy," Transactions of Nonferrous Metals Society of China, vol. 21, no. 12, pp. 27902797, 2011.

[18] V. R. Reddy, B. Dixit, and K. Udaya Bhat, "Effect of deposition time on the characteristics of high phosphorous nickel deposit, deposited using electroless route," Materials Science Forum, vol. 710, pp. 671-676, 2012.

[19] E. A. Brandes and G. B. Brook, Smithels Metals Reference Handbook, Butterworth Heinemann Publications, 17th edition, 1992.

[20] Y. D. He, H. F. Fu, X. G. Li, and W. Gao, "Microstructure and properties of mechanical attrition enhanced electroless Ni-P plating on magnesium alloy," Scripta Materialia, vol. 58, no. 6, pp. 504-507, 2008.

[21] M. Palaniappa and S. K. Seshadri, "Structural and phase transformation behaviour of electroless Ni-P and Ni-W-P deposits," Materials Science and Engineering A, vol. 460-461, pp. 638-644, 2007.

[22] S. H. Park and D. N. Lee, "A study on the microstructure and phase transformation of electroless nickel deposits," Journal of Materials Science, vol. 23, no. 5, pp. 1643-1654, 1988.

[23] J. Li, Y. Tian, Z. Huang, and X. Zhang, "Studies of the porosity in electroless nickel deposits on magnesium alloy," Applied Surface Science, vol. 252, no. 8, pp. 2839-2846, 2006.

[24] J. Liu, X. Zhu, J. Sudagar, F. Gao, and P. Feng, "Preparation and corrosion resistance of electroless Ni-P coating on open cell aluminium foams," International Journal of Electrochemical Science, vol. 7, pp. 5951-5961, 2012.

[25] P. H. Lo, W. T. Tsai, J. T. Lee, and M. P. Hung, "Role of phosphorus in the electrochemical behavior of electroless Ni$\mathrm{P}$ alloys in 3.5 wt.\% $\mathrm{NaCl}$ solutions," Surface and Coatings Technology, vol. 67, no. 1-2, pp. 27-34, 1994. 

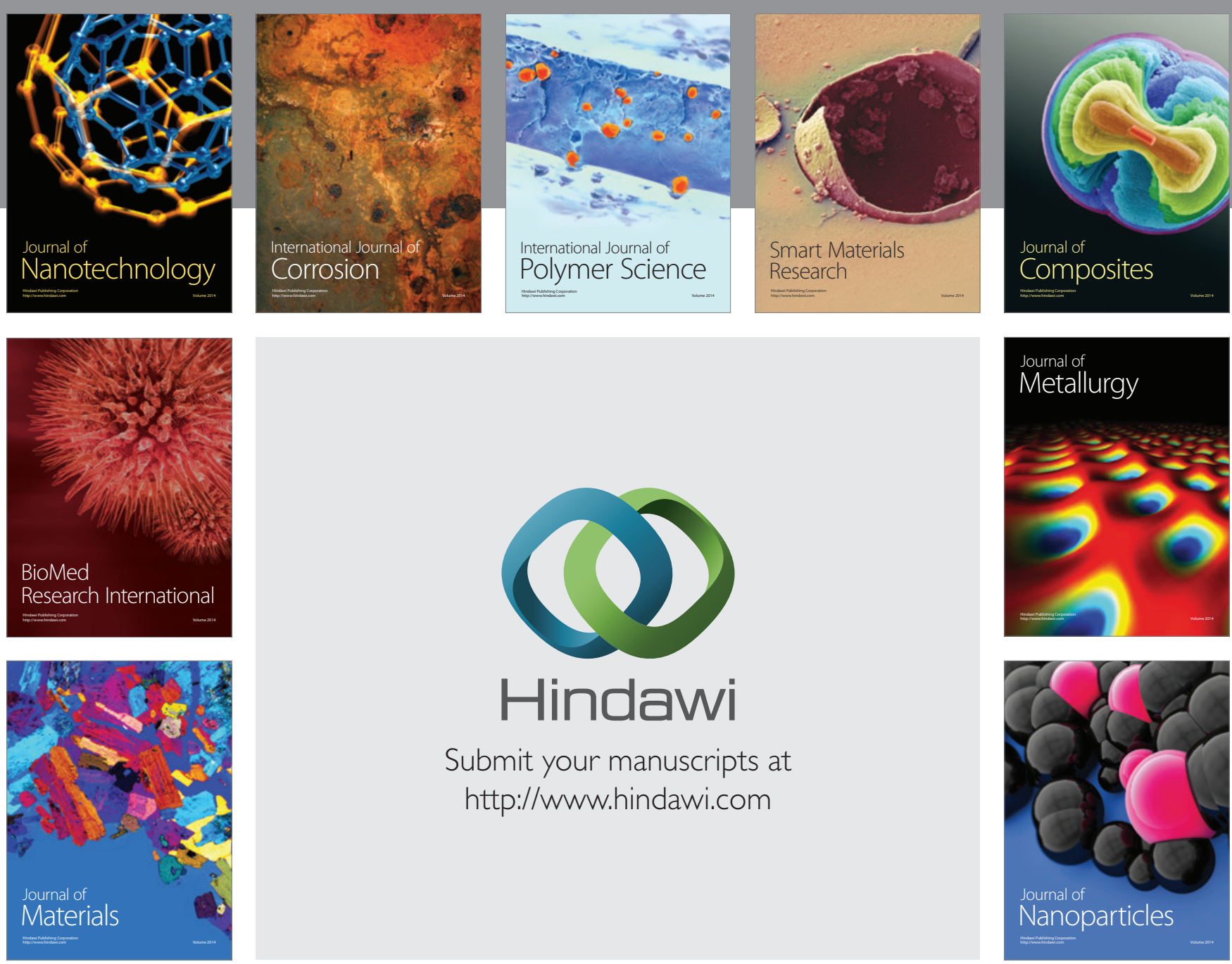

Submit your manuscripts at http://www.hindawi.com
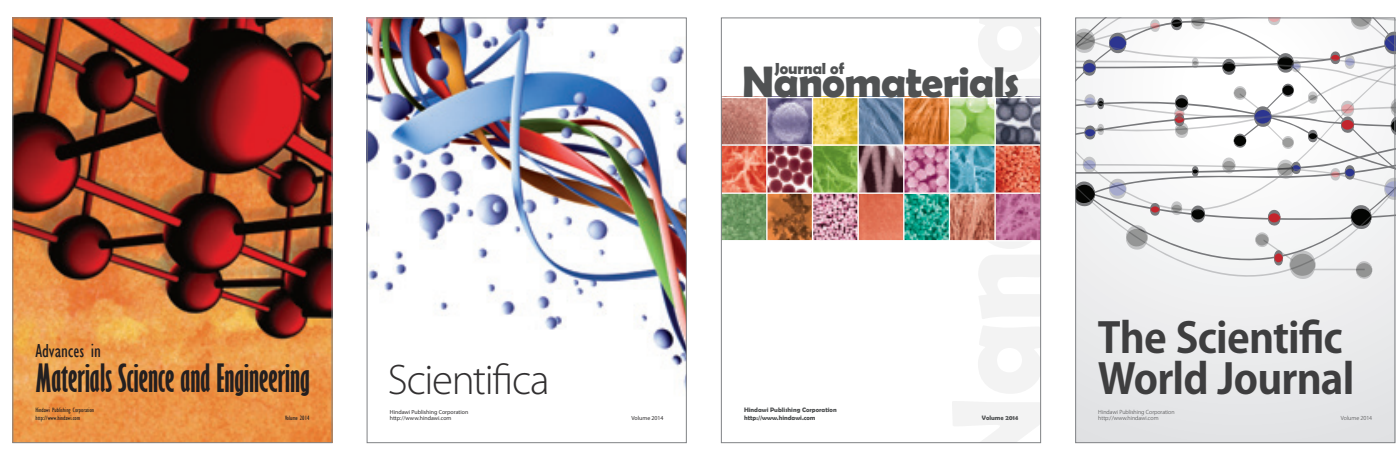

\section{The Scientific World Journal}
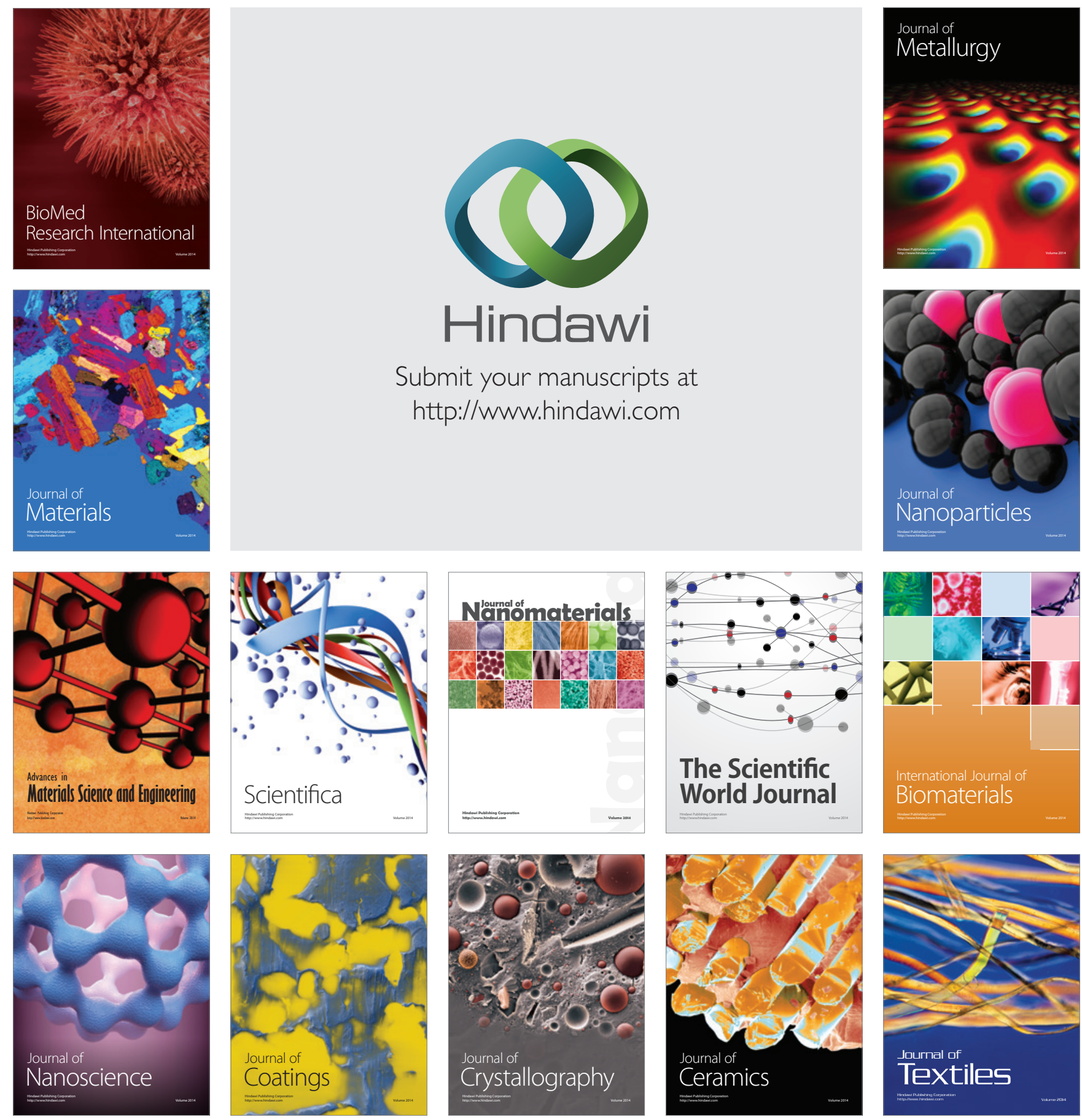